\title{
Climate Effects on Cooling Degree-Hours and Evaporative Cooling of Gas Turbine
}

\author{
Dayyabu Gambo Kofar-Bai and Qun Zheng
}

\begin{abstract}
Increase demand of power during peak load hours necessitates the need to raise gas turbine power plant performance especially in a region or station with persistant high temperature and low relative humidity, in this paper climatic data of some particular stations in Nigeria were modeled, cooling degre-hours obtained were simulated on brayton simple cycle and evaporative cooling of gas turbine, performance effects were studied and presented, the results shows an increase in the gas turbine power and efficiency and decrease of compression work on the compressor, evaporative cooling retain the net output power of the gas turbine to $\mathbf{2 5 . 8 6}$ MW at higher temperature when the demand is at peak and increases the efficiency to $29.8 \mathrm{MW}$ when the demand is low and the ambient temperature at lowest level. Cooling degree-hours decrease with increase in base temperature and with known cooling degree-hours in a station,net power can not only be boost but the operational cost of evaporative cooling of gas turbine can be reduce.
\end{abstract}

Index Terms-Evaporative cooling, cooling degree-hours, climate and gas turbine.

\section{INTRODUCTION}

Gas Turbine have gained widespread acceptance in the power generation,mechanical drive and gas transmission. improvements in hot section materials, cooling technologies and aerodynamics have allowed increase in firing temperatures, consequently, thermal efficiencies are currently very attractive with simple cycle efficiencies ranging from 32 to 42 percent and combined cylce efficiencies reaching 60 percent mark [1].

Gas turbine performances efficiences and net output power are strong functions of ambient or sorrounding temperature, climatic weather posses a great influences on gas turbines, with a record of 15 to 20 percent output drop in hot and arid climates [2]. Among the alternative solutions employed to maintain or attain the requred output is cooling the inlet air, to cool the inlet air it requre morethan evaporative cooling, inlet fogging,wet compression or intercoolers, reheaters and regenarators, it requires a comprehensive knowledge of the climatic weather, hourly temperature record, cooling degree-hours, monthly and annual temperature varaition and humidty [3].

The objective of this research is a case study of selective stations in Nigeria and the paper is intended to eavaluate and analyse data from average hourly daily temperature, annual cooling degree-hours and simulation of the data in to

Manuscript received May 25, 2016; revised December 16, 2016.

The authors are with Harbin Engineering University, China (e-mail: nagari2010@gmail.com). evaporative gas turbine engine.

Air-conditioning and refrigeration, evaporative cooling and wet compression of gas turbine design engineers, local or exporting companies needs a comprehensive design climatic data in designing for indoor comfort or augmenting the turbine at peak load especially in regions with high temperature and low humidity. Cooling and heating degree-hours or cooling and heating degree-days play significant roles in managing air-conditioning equipment, energy planning (both generation and consumption) and estimating cooling and heating loads [4]. Erbs used twenty years hourly data for nine locations across United States of America to compute cooling degree-days for base temperature between $10^{\circ} \mathrm{C}$ and $29^{\circ} \mathrm{C}$. Thermal efficiency is one of the important parameters among gas turbine cycles and has a major impact on the operating cost, especially due to the limited resources of fuel [5]. Recently, concerted efforts have been made in different areas of gas turbine technologies with main objective of improving the cycle efficiency, various means have been employed by many researchers to improve the thermal efficiency and net output power of the gas turbines. One of the means is to use intercooler; the intercooler is used to reduce the temperature of air that enters to high pressure compressor (HPC). The intercooling is especially effective when used in a cycle with regenerator [6]. Alhazmy et al. [7] evaluated in their study of the performance of gas turbine operating in hot humid conditions of Jeddah Saudi Arabia that the average power output of the plant increases by $0.57 \%$ for each $1{ }^{\circ} \mathrm{C}$ drop in ambient air temperature. The power output is increased by 10 percent humid condition. Shahrokh S. developed a thermodynamic model for a typical simple cycle $25 \mathrm{MW}$ gas turbine industrial plant with intercooler, reheat and regenerator, the model increase the output power and thermal efficiency [8].

Power generations plant becomes more competitive every day and a growing interest the power capacity output without the large capital investment associated with the addition of new capacity. One of the reliable methods employed for power augmentation methods is evaporative cooling.

Evaporative coolers are used with gas turbines to increase the density of the combustion air, thereby increasing net power output. this method is achieved through evaporating water in to the inlet air, thereby decreasing its temperature and corespondingly increases its denstiy [9]. it is highly recommended to purify the water in order to prevent corrosion of the compressor blades and its components.

Evaporative cooling shows that turbine output and heat rate is improved as compressor inlet temperature decreases. The biggest gains from evaporative cooling are realized in hot, low-humidity climates. It should be noted that evaporative 
cooling is limited to ambient temperatures $15^{\circ} \mathrm{C}$ and above (compressor inlet temperature because of the potential for icing the compressor) [10].

\section{DAta AND Methodology}

It is always recommendable to use the daily average annual temperature profile when analaysing a particluar enviromental case study, a 25 years average of daily temperature and relative humidity for the entire 37 stations were used to calculate the potential of cooling degree-hours at various base temperature and the summary of the results is tabulated and presented in Table II of the Appendix. The data were collated from the Archive unit of the Nigerian Meteorological Agency (NIMET) and analyzed for the study. Monthly cooling degree-hours (CDH) were tabulated on spreadsheet and the summation provides the annual cooling degree-hour. Those stations located in arid zones are with higher cooling degree-hours as shown in Table II, were simulated using Engineering Equation solver (EES) for dry and evaporative gas Turbine and the results are presented in figures and in Tables. Operation parameters of the gas turbine, results comparison for dry and evaporative air at room and peak temperature were presented in Table I.

\section{THERMODYNAMIC EQUATIONS}

Gas turbine is an engine in which atmospheric air is continuously drawn into the compressor where it is compressed to a high pressure. Humidified air entering the compressor at point 1 is compressed to some higher pressure. No heat is added; however, compression raises the air temperature so that the air at the discharge of the compressor is at a higher temperature and pressure. Upon leaving the compressor, air enters the combustion system at point 2, where fuel is injected and combustion occurs. The combustion process occurs at essentially constant pressure [10].
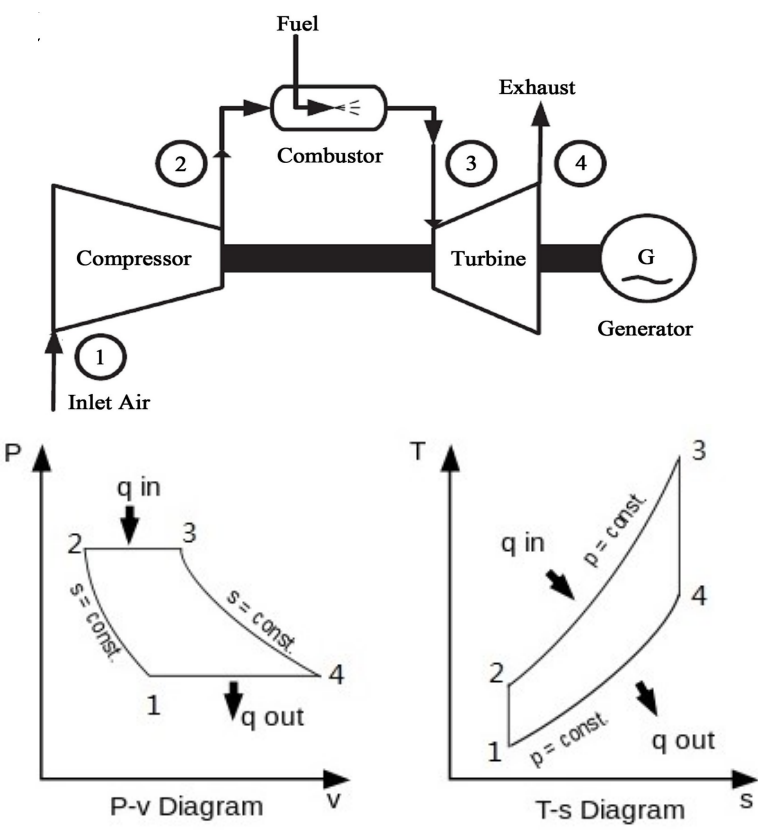

Fig. 1. Simple cycle gas Turbine with P-v and T-s.
Although high local temperatures are reached within primary zone, the combustion system is designed to provide mixing, burning, dilution and cooling. In the turbine section of the gas turbine, the energy of the hot gases is converted into work some of the work developed by the turbine is used to drive the compressor, and the remainder is available for useful work at the output flange of the gas turbine. Typically, more than $50 \%$ of the work developed by the turbine sections is used to power the axial flow compressor.

Fig. 1 shows a typical Brayton simple cycle. The thermodynamic equation of the compressor efficiencies work and can be obtained in equation (1) [11]. The compressor and turbine isentropic efficiency are given to be 0.82 and 0.86 respectively, and the mass flow rate $\dot{m}$, then the isentropic compressor and turbine work can be expressed in terms of enthalpies.

Given the pressure ratio, the pressure at the exit of compressor is express as:

$$
p_{2}=p_{r}^{*} p_{1}
$$

The temperature at compressor exit:

$$
\begin{gathered}
T_{2}=T_{1}+\left(\frac{T_{S 2}-T_{1}}{\eta_{C}}\right) \\
\dot{w}_{c}=\dot{m}_{a} c_{p a}\left(h_{2}-h_{1}\right) \\
p_{3}=p_{2} *\left(1-\Delta p_{c o m b}\right) \\
\mathcal{W}_{t}=m_{T} c_{p a}\left(h_{3}-h_{4}\right) \\
m_{T}=\dot{m}_{a}+\dot{m}_{f}
\end{gathered}
$$

The actual compressor, turbine and network are given by equation (7) and (8) and the net work done by the system in equation (9).

$$
\begin{gathered}
\dot{w}_{c, a}=\dot{w}_{c}^{*} \eta_{c} \\
\dot{w}_{t, a}=\dot{w}_{t}^{*} \eta_{t} \\
\dot{w}_{\text {net }}=\dot{w}_{t, a}-\dot{w}_{c, a}
\end{gathered}
$$

The enthalpy of combustion of the gases at any temperature is given by the equation (10) [11] and the fuel used in the combustion is natural gas (methane) $\mathrm{CH}_{4}$, the enthalpy is given by zero value of the ambient pressure 1 bar and temperature of $15^{\circ} \mathrm{C}$.

$$
h=\int_{t_{0}}^{t}\left[C_{p_{c o 2}}(T)+C_{p_{H_{2} 0}}(T)+C_{p N_{2}}(T) d T\right.
$$

And the combustion reaction equation with oxygen balance $A_{\text {th }}$ is given by equation (11):

$$
\mathrm{CH}_{4}+A_{t h}\left(\mathrm{O}_{2}+3.76 \mathrm{~N}_{2}=1 \mathrm{CO}_{2}+2 \mathrm{H}_{2} \mathrm{O}+A_{t h}(3.76) \mathrm{N}_{2}\right.
$$


According to the first law of thermodynamic, heat balance in the combustion chamber is calculated by the equation (12) [11]

$$
\dot{Q}=\sum_{p} n_{\text {out }}\left(\overline{h_{f}^{o}}+\Delta \bar{h}\right)-\sum_{R} n_{\text {in }}\left(\overline{h_{f}^{o}}+\Delta \bar{h}\right)
$$

The mass flow rate of the fuel, specific fuel consumption and air fuel ratio are computed in equation (13) to (14), the mass of air entering turbine is $40 \%$ of the air leaving compressor.

$$
\begin{gathered}
m_{f}=\frac{\dot{Q}_{i n}}{L H V^{*} \eta_{c}} \\
S F C=\frac{3600^{*} m_{f}}{\dot{w}_{n e t}} \\
A F R=\frac{\dot{m}_{a}}{\dot{m}_{f}}
\end{gathered}
$$

The thermal efficiency of the gas turbine is calculated by equation (16):

$$
\eta_{t h}=\frac{\dot{w}_{n e t}}{\dot{Q}_{i n}}
$$

\section{EVAPORATIVE COOLER EQUATIONS}

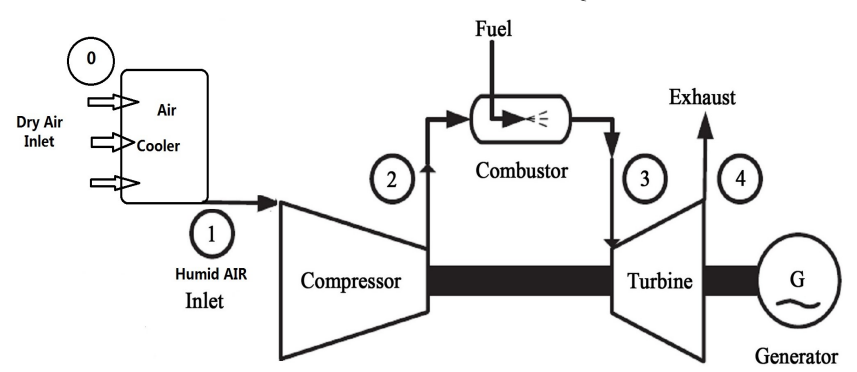

Fig. 2. Gas turbine cycle with evaporative cooler.

Fig. 2 shows mechanism diagram of evaporative cooling, which takes the advantages of the principles of latent heat of evaporation where tremendous heat is exchanged when water evaporates. It make use of free latent heat of energy in the atmosphere, the hotter the outside temperature and the lower the humidity, the greater will be the cooling effect.

Water is brought in to the cooler from the main water supply and is pumped up to the top of the unit using water distribution system which allows the water to flow continually over the pad. The pads become saturated, air is drawn through the pads and the water evaporates causing the air to cool. The cool air then ducted out by means of axial fan [10].

Applying mass and energy balance on air cooler, given the atmosphere relative humidity $\phi$, then moisture content or steam-to-air ratio is given in equation (17).

$$
\omega_{0}=\frac{m_{v} p_{v}}{m_{a} p_{a}}=0.622 \frac{\phi p_{s v}}{p-\phi p_{s v}}
$$

where $m_{v}, p_{v}$ are mass and pressure of vapor, $m_{a}, p_{a}$ are mass and pressure of air respectively and the subscript $s v$ represents saturation state. The change in enthalpy when the inlet air is humidified is given by equation (18) [4].

$$
\left(h_{1}-h_{0}\right)=\left(\omega_{1}+\omega_{0}\right) h_{f, 0}
$$

Taking the specific latent heat constant we have

$$
\begin{gathered}
{\left[1.005 t_{1}+\omega_{1}\left(2501+1.859 t_{1}\right)\right]^{-}} \\
{\left[1.005 t_{0}+\omega_{0}\left(2501+1.859 t_{0}\right]=\left(\omega_{1}-\omega_{0}\right) h_{f, 0}\right.}
\end{gathered}
$$

Where specific heat of air, vapor at constant pressure and latent;

$$
\begin{gathered}
G_{p, a}=1.005 \mathrm{~kJ} / \mathrm{Kg} \cdot \mathrm{K}, C_{p s}=1.859 \mathrm{~kJ} / \mathrm{kg} . \mathrm{K} \\
L_{0} H_{2} 0=2501 \mathrm{~kJ} / \mathrm{kg} . \mathrm{K}
\end{gathered}
$$

The evaporative cooler specific humidity is given by:

$$
\omega_{1}=0.622 \frac{p_{s v}}{p-p_{s v}}
$$

\section{CoOling Degree Hours Equation}

Cooling degree-hours are defined as the sum of the difference between hourly average temperatures and the base temperature, the number of cooling degree hours is defined by the equation 21 in accordance with the refrence [12].

$$
C D H_{b}=\sum_{i=1}^{N}\left(T_{i}-T_{b}\right)^{+}
$$

where $N$ is the number of hours in the day, $T_{i}$ is the average hourly temperature, $T_{b}$ is the base temperature of which the degree days are calculated. The "+" superscript sign indicate only positive values of the bracketed components are taken in to account in the sum.

\section{RESULTS AND DISCUSSION}

This paper presentation have analyzed climatic characteristics and its effects on cooling degree-hours, daily hours temperature, net power output and efficiencies performances of gas Turbine in aird zone locations

Fig. 3 shows daily hours temperature variation of three stations from Table II, it is obvious and natural that in Arid zone locations, temperature climax during the day late afternoon when the relative humidty is at lower level and temperature drops at night time when the relative humidity is at higher level, this parculiar climatic trend is not so good for the gas turbine output, and resulted in to low power output when the demand is at peak. The minimum recorded temperature of $24^{\circ} \mathrm{C}$ usually at early morning hours while the maximum ranging from $40^{\circ} \mathrm{C}$ to $44^{\circ} \mathrm{C}$ respectively at late afternoon in the selected stations. A bar chart corelation shown in Fig. 4 shows a cooling degree-hours of the three stations against base temperature(s), aimed to provide refrence cooling index at various temperatures, maximum of 6796, 6456 and 6104 at stations with base temperature of $24^{\circ} \mathrm{C}$ were observed, the trend decreases across the refrence base temperature. From these two afore-mentioned graphs it requires 12-16 hours of daily cooling to maintain comfort and 
operational atmosphere for the gas turbine during the time in question.

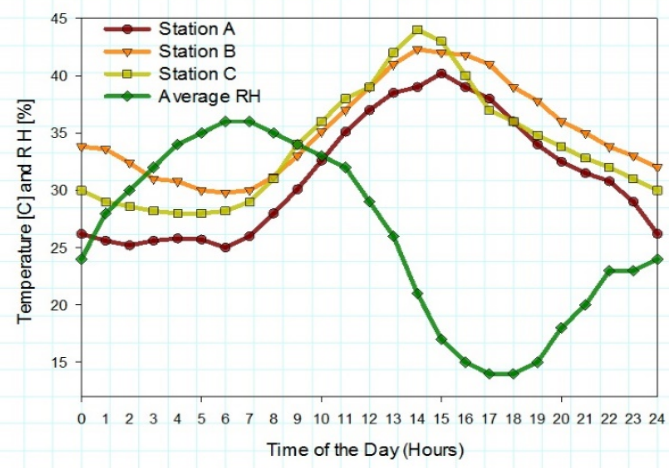

Fig. 3. Shows daily effects of temperature against hours of the day.

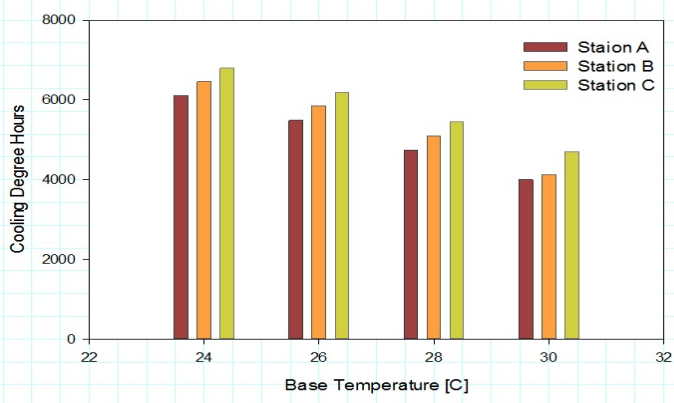

Fig. 4. Shows cooling degree-hours against base temperature.

Fig. 3 \& Fig. 4 show daily effects of temperature and relative humidity versus hours of the day and cooling degree-hours versus base temperature respectively. The stations $\mathrm{A}, \mathrm{B}$ and $\mathrm{C}$ are Kano, Borno and Sokoto respectively.Details is shown in Table II, these stations are located in arid zone areas at various latitudes and longitudes and are among those with maximum cooling degree-hours.

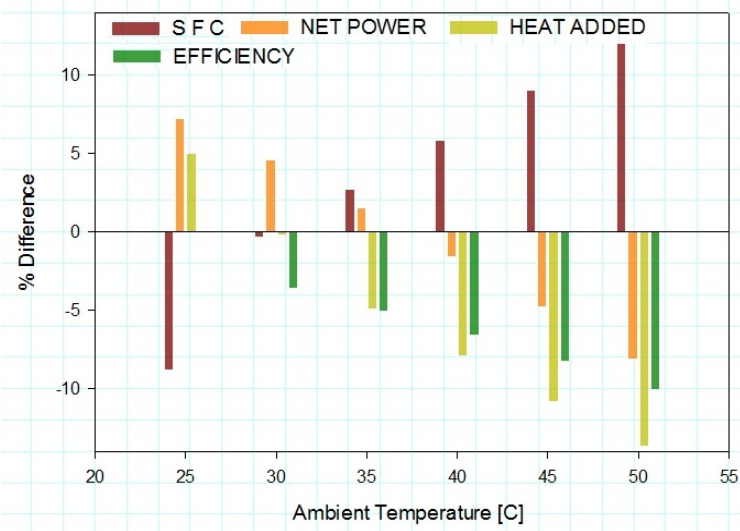

Fig. 5. Shows the effects of ambient temperature of simulated simple (dry) gas turbine cycle with respect to design values.

Fig. 5 and Fig. 6 highlights a bar chart of percentage differences for simple cycle (dry) and evaporative cooling of gas turbine respectively, the effects of evaporative cooling on specific fuel consumption (SFC), net power output, Heat added and efficiency of the gas turbine at various ambient temperature, the simulated parameters are with resepct to the design operational values of the manufacturer shown Table I. From the two graphs above two scenarious were drawn:
TABLE I: COMPARING Simulated VALUES WITH Design VALUES OF THE GAS TURBINE CYCLE

\begin{tabular}{|l|l|l|l|l|l|}
\hline S/N & $\begin{array}{l}\text { Operating } \\
\text { parameters }\end{array}$ & $\begin{array}{l}\text { Design } \\
\text { values }\end{array}$ & \multicolumn{2}{|l|}{$\begin{array}{l}\text { Simulated values at ambient } \\
\text { Temperatures }\end{array}$} \\
\hline & & & $25^{\circ} \mathrm{C}$ & $45^{\circ} \mathrm{C}$ & $45^{\circ} \mathrm{C}$ \\
\hline 1 & $\begin{array}{l}\text { GT Net Output } \\
\text { Power[MW] }\end{array}$ & 25.00 & 26.19 & 20.20 & 25.86 \\
\hline 2 & GT Efficiency[\%] & 38.00 & 34.93 & 30.56 & 35.25 \\
\hline 3 & Heat added [KW] & 69,700 & 74,962 & 66,091 & 73,345 \\
\hline 4 & Evaporative cooling & - & - & NO & YES \\
\hline 5 & $\begin{array}{l}\text { Compressor inlet } \\
\text { Tempt. [C] }\end{array}$ & 25 & 25 & 45 & 31.57 \\
\hline 6 & $\begin{array}{l}\text { Compressor exit } \\
\text { Tempt.[C] }\end{array}$ & 820 & 804.7 & 912.8 & 822.5 \\
\hline 7 & $\begin{array}{l}\text { Specific fuel } \\
\text { consumption[kg/KJ] }\end{array}$ & 0.69 & 0.687 & 0.8912 & 0.6962 \\
\hline 8 & $\begin{array}{l}\text { Compressor Work } \\
{[\text { KW] }}\end{array}$ & 45,600 & 39,984 & 45,973 & 40,960 \\
\hline 9 & Turbine Work[kW] & 72,000 & 66,171 & 66,171 & 66,815 \\
\hline 10 & $\begin{array}{l}\text { Compressor } \\
\text { Pressure Ratio }\end{array}$ & 21.44 & 21.44 & 21.44 & 21.44 \\
\hline 11 & $\begin{array}{l}\text { Mass flow rate of } \\
\text { air[kg/s] }\end{array}$ & 86.9 & 87.8 & 97.3 & 83.5 \\
\hline 12 & $\begin{array}{l}\text { Mass flow rate of } \\
\text { fuel[kg/s] }\end{array}$ & 2.28 & 2.257 & 1.99 & 2.208 \\
\hline & & & & & \\
\hline
\end{tabular}

TABLE II: ANNUAL COOLING DEgREe-Hours For 37 StATIONS

\begin{tabular}{|l|c|c|c|c|}
\hline Stations & \multicolumn{4}{|c|}{ Base Temperature $\left({ }^{\circ} \mathbf{C}\right)$} \\
\hline Abia & 24 & 26 & 28 & 30 \\
\hline Adamawa & 2643.4 & 1956.1 & 1212.1 & 567.3 \\
\hline Akwaibom & 5092 & 4467.1 & 3723.1 & 2907.8 \\
\hline Anambra & 3155.4 & 1562.4 & 843.2 & 406.1 \\
\hline Bauchi & 5396.6 & 2483.1 & 1739.1 & 1047.8 \\
\hline Bayelsa & 2057.9 & 1357.8 & 629.3 & 164.3 \\
\hline Benue & 3730.5 & 3075.2 & 2331.2 & 1643 \\
\hline Borno & 6456.2 & 5849.7 & 5105.7 & 4126.1 \\
\hline CrossRiver & 1723.4 & 1016.8 & 375.1 & 24.8 \\
\hline Delta & 3116.1 & 2442.8 & 1698.8 & 1007.5 \\
\hline Ebonyi & 2998.3 & 2325 & 1581 & 1004.4 \\
\hline Edo & 2986.5 & 2309.5 & 1565.5 & 895.9 \\
\hline Ekiti & 3308.9 & 2641.2 & 1897.2 & 1230.7 \\
\hline Enugu & 3155.1 & 2483.1 & 1739.1 & 1047.8 \\
\hline Abuja & 3856.5 & 3205.4 & 2461.4 & 1850.7 \\
\hline Gombe & 5453.7 & 4832.9 & 4088.9 & 3344.9 \\
\hline Imo & 2747.4 & 2064.6 & 1320.6 & 675.8 \\
\hline Jigawa & 5801.6 & 5183.2 & 4439.2 & 3695.2 \\
\hline Kaduna & 4058.4 & 3410 & 2666 & 2021.2 \\
\hline Kano & 6104.8 & 5490.1 & 4746.1 & 4002.1 \\
\hline Katsina & 5808.8 & 5189.4 & 4445.4 & 3701.4 \\
\hline Kebbi & 6605.1 & 6001.6 & 5257.6 & 4513.6 \\
\hline Kogi & 3545 & 2883 & 2139 & 1438.4 \\
\hline Kwara & 3841.8 & 3186.8 & 2442.8 & 1751.5 \\
\hline Lagos & 2217 & 1522.1 & 809.1 & 303.8 \\
\hline Nasarawa & 3959.5 & 3310.8 & 2566.8 & 1897.2 \\
\hline Niger & 4300.7 & 3658 & 2914 & 2216.5 \\
\hline Ogun & 3191.3 & 2520.3 & 1776.3 & 1109.8 \\
\hline Ondo & 3308.9 & 2641.2 & 1897.2 & 1230.7 \\
\hline Osun & 3145.6 & 2473.8 & 1729.8 & 1088.1 \\
\hline Oyo & 3191.3 & 2520.3 & 1776.3 & 1109.8 \\
\hline Plateau & 3895 & 3245.7 & 2501.7 & 1887.9 \\
\hline Rivers & 2005.9 & 1305.1 & 585.9 & 136.4 \\
\hline Sokoto & 62395.9 & 6193.8 & 5449.8 & 4705.8 \\
\hline Taraba & 3592.9 & 2848.9 & 2154.5 \\
\hline Yobe & 5676.1 & 4932.1 & 4188.1 \\
\hline Zamfara & 5229.7 & 4485.7 & 3741.7 \\
\hline
\end{tabular}

When the ambient temperature is less or eqaul to $30^{\circ} \mathrm{C}$, from Fig. 5 moderate heat added to the system and efficiency of $36.7 \%$ was achieved,where as Fig. 6 there was less fuel consumption more heat added to the system and net power reaches $29.8 \mathrm{MW}$ equivalent to $8.9 \%$ increase with efficiency value of $38.4 \%$. 


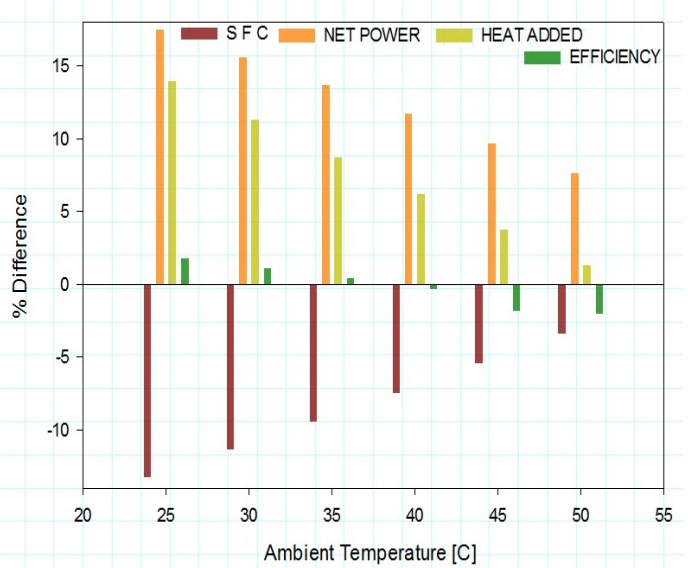

Fig. 6. Shows effect of evaporative cooling on SFC, net power output, heat rate and efficiency of gas turbine at various ambient temperatures.

When the ambient temperature is/and above $30^{\circ} \mathrm{C}$ Fig. 5 due to higher temperature above operational value couple with low humidity brough more fuel consumption less heat and lower efficiency to the system thereby making the system performance below operational values while in Fig. 6 higher temperature and good level of humidity at the exit of evaporative cooler added more heat to the system and increases the efficency untill when the ambinet temperature reaches above $45^{\circ} \mathrm{C}$, then and thereafter the system still have the capacity to retained the power and efficiency close to design level.

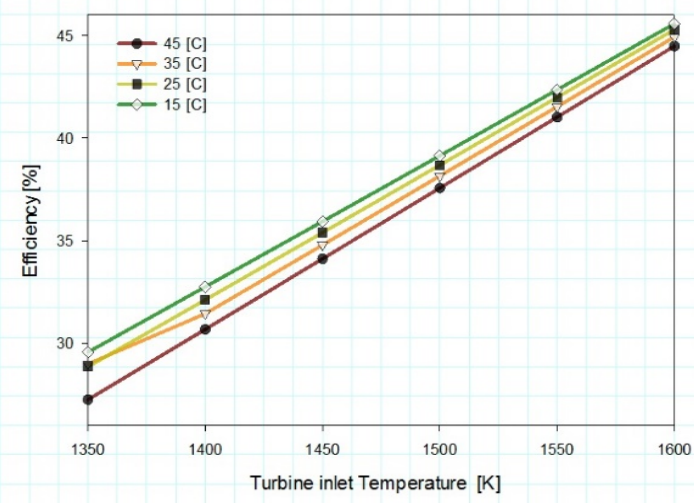

Fig. 7. Variation of efficiency of the evaporative gas turbine with Turbine inlet temperature.

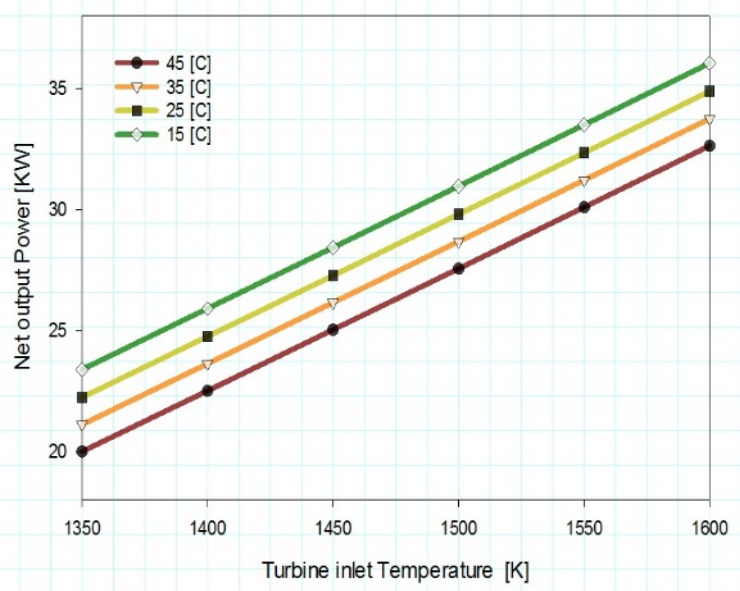

Fig. 8. Variation of net power output of the evaporative gas turbine with Turbine inlet temperature.
Fig. 7 and Fig. 8 show the effect of turbine inlet temperature on thermal efficiency of evaporative gas turbine and net output power at various ambient temperatures.

Efficiency and net output power increases with increase in turbine inlet temperature TIT at various inlet ambient temperatures, similarly, lower ambient temperature means lower compressor inlet temperature and less energy consumed in compression work, hence more heat is added to the turbine and resulted to higher net output power and efficiency of the system. Evaporative cooling is limited to ambient temperature of $15^{\circ} \mathrm{C}$ and above because of the potential for icing the compressor. Moreover, turbine inlet temperature is also limited by metallurgical property used by the manufacturer, hence, the maximum requirement temperature for this system was limited to $1514[\mathrm{~K}]$ as shown in Table I. The results obtained correspond to the result of Anoor and S. Oyedepo in reference [13] and [14].

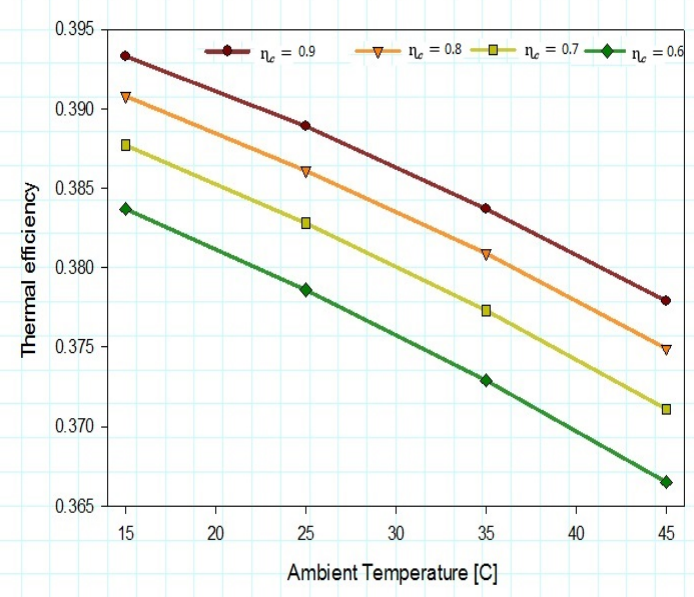

Fig. 9. Effects of ambient temperature on thermal efficiency at different compressor effectiveness

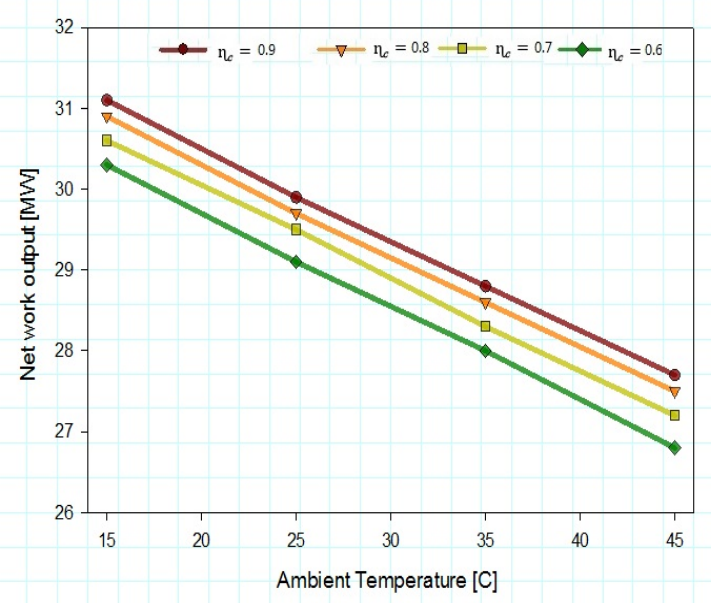

Fig. 10. Effects of ambient temperature on net output power at different compressor effectivenss

Evaporative cooling of gas turbine decreases the compression work of the compressor and increases the efficiency of the system, that means compressor effectivenss is also another factor to be consider on simulations Fig. 9 highlight the effects of ambient temperature on thermal efficiency at different compressor effectivess, from the Fig. 10 it shows that the greater the effectives the higher the 
efficiency and the the trend decreases as the ambient temperature increases, similarly, the network output is also affected with compressor effectiveness variation, the higher the effectivess the better the network output, more importantly even as the ambient temperature increases the network value still retain above $26 \mathrm{MW}$.

\section{CONCLUSION}

Climate data and evaporative model gas turbine has been modelled, daily and annual cooling degree-hours and influences of climate on the net power, fuel consumption, heat added and efficiency were evaluated and the results indicates that; effective cooling can be achieved through evaporative cooling of inlet air and such cooling effect reduce the compression work of compressor and increases the net output power of the gas turbine, moreover characteristic climate with high temperature brings higher cooling degree-hours and effectiveness of evaporative cooling. From the annual cooling degree-hours at base temperature $24^{\circ} \mathrm{C}$ cooling degree-hours of 12-16 hours can reduce the cost operational cost of evaporative cooling by installing $\mathrm{ON}$ and OFF switch. ON to operate when the temperature is above base value and OFF when the temperature is below

\section{APPENDIXES}

Appendix Table I highlight comparison of the lost and gain of power and efficiency on operation parameters of the design gas turbine with simulated values at various ambient temperatures with and without evaporative cooling. The tables also show the influence of the climatic temperature on the performance of gas turbine and the reasons behind evaporative cooling for effective recovery of the lost power.

\section{ACKNOWLEDGEMENT}

The author would like to acknowledge the support of Tertiary Education Trust Fund (Tetfund) Nigeria .The author would also like to thanks the reviewers for their valuable comments and suggestion.

\section{REFERENCES}

[1] C. B. Meher-Homji and T. R. Mee, "Gas turbine power augmentation by fogging of inlet air," in Proc. $28^{\text {th }}$ Turbo-Machinery Symposium, Texas A\&M University, 2006, vol. 45, pp. 829-840.

[2] R. Bhargava and A. Peretto, "A unique approach for thermos-economic optimization of an intercooled, reheat, and recuperated gas turbine for cogeneration applications," J. Engineering and Gas Turbine Power, vol. 124, pp. 881-891, 2002.

[3] Mustapha et al., "Inlet fogging of gas turbine engines. Climatic analysis of gas turbine evaporative cooling potential of international locations," Journal of Engineering for Gas Turbines and Power, vol. 128 , p. 815 , October 2006

[4] Q. Zheng et al., "Thermodynamic analysis of wet compression process in the compressor of gas turbine," Journal of Turbo-Machinery, vol. 125 , p. 489, July 2003.

[5] S. K. Tyagi et al., "Thermodynamic analysis and parametric study of an irreversible regenerative-intercooled-reheat Brayton cycle," International Journal of Thermal Sciences, vol. 45, pp. 829-840, 2006.

[6] R. Yadav et al., "Thermodynamic analysis of intercooled gas-steam combined and steam injected gas turbine power plants," in Proc. ASME TURBO EXPO: Power for Land Sea and Air, Vienna Austria, 2004.

[7] M. M. Alhazmy and Y. S. H. Najjar, "Augmentation of gas turbine performance using air coolers," Applied Thermal Engineering, vol. 24, pp. $415-429$.

[8] S. M. Shahrokh and R. Sharifabadi, "Thermodynamic investigation of typical 25MW simple cycle gas turbine and effectiveness evaluation of intercooler, reheat and regenerator," in Proc. Asian Conference on Gas Turbine, October 2012.

[9] R. S. Johnson, "The theory and operation of evaporative coolers for industrial gas turbine installations," ASME $88 G T$.

[10] F. J. Brooks, "Gas turbine performance characteristics," GE Power System Schenectady, New York.

[11] Y. A. Cengel, An Engineering Approach Thermodynamic Book, Seventh edition, McGraw-Hill Higher Education, 2006, ch. 9

[12] K. Assawamartbunle, "An investigation and cooling and heating degree HOURS in Thailand," Journal of Clean Energy and Technology, vol. 1, no. 2, April 2013.

[13] A. Kumar et al., "Effects of compressor inlet temperature and relative humidity on gas turbine cycle performance," International Journal of Scientific \& Engineering Research, vol. 5, issue 5, May 2014.

[14] S. O. Oyedepo, "Thermodynamic analysis of a gas turbine power plant modeled with an evaporative cooler," International Journal of Thermodynamics, vol. 17, no. 1, pp. 14-20, 2014.

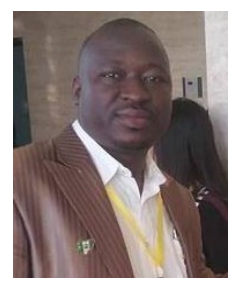

Dayyabu Gambo Kofar-bai obtained his bachelor degree in mechanical engineering from Bayero University, Kano, Nigeria in June 2006 and master's degree in marine engine engineering at Harbin Engineering University, China, July 2010

$\mathrm{He}$ is currently pursuing his $\mathrm{PhD}$ degree in the field of power engineering and engineering thermophysics at College of Power and Energy, Harbin Engineering University, China. $\mathrm{He}$ is also a lecturer at the Department of Mechanical Engineering, Hassan Usman Katsina Polytechnic, Katsina, Nigeria

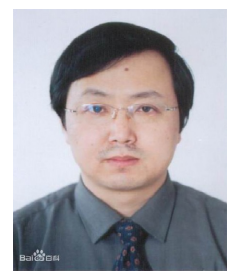

Qun Zheng is a professor of the College of Power and Energy Engineering, Harbin Engineering University 150001 China. He obtained his bachelor degree in marine engineering at Harbin Ship Building Engineering Institute, 1984, MSc degree at Harbin Institute of Technology, 1987 and Ph.D. degree at Harbin Engineering University, 2000 in the field of turbo machinery.

His research interest includes thermodynamics, aerodynamics, gas turbine and steam power plant etc.

$\mathrm{He}$ is a committee member of industrial cogeneration, American society of Mechanical Engineers (ASME) and International Gas Turbine Institute (IGTI). 